\title{
Productivity of Words with Negative Affixes in English- Albanian and Albanian-English Dictionaries
}

\author{
Dr. Miranda Enesi
}

Aleksandër Moisiu University; mirashahini@gmail.com

\author{
Dr. Ekaterina Strati
}

Aleksandër Moisiu University; ekaterina_gjergo@yahoo.co.uk

\section{Doi:10.5901/jesr.2016.v6n1p78}

\begin{abstract}
Lexicography has attracted the attention of scholars interested in analyzing the formation of words and their semantics, for centuries. The role of all negative affixes in bilingual dictionaries is not widely discussed. In various articles statistical information with regard to all the words with negative affixes existing in the source and target languages is scarce. Bilingual dictionaries reflect the richness of language lexicon, based on national rates and contemporary linguistic theory. In this paper we do not only aim to provide a simple statistic comparison, but to highlight the productivity of words with negative affixes in English and Albanian, as well the richness of lexicon in both languages. As linguistic corpus we have reviewed, analyzed and compared English-Albanian and Albanian-English dictionaries of different types. The compilation and editing of bilingual dictionaries today is an organized and systematic activity based on the experience of practical lexicography, and current theoretical principles around the world. By a detailed analysis we have concluded that the productivity of these words in Albanian-English and English-Albanian dictionaries is almost equal. These words are also stylistically esteemed. They provide more force, and persuasion to discourse.
\end{abstract}

Keywords: Dictionary, negative affixes, productivity, English, Albanian.

\section{Introduction}

This study focuses on the morphological and semantic phenomena of words with negative affixes. The measurement of their use in both languages is realized in details in order to highlight the importance these words represent in English and Albanian lexicon. It has been analyzed the lexicographic reflection of these words in three English-Albanian and three Albanian-English dictionaries of big, medium and small types counting every word with negative affix in these dictionaries and the results show that words with negative prefixes in bilingual dictionaries produce an approximate number of words, whereas the words with negative suffixes even though in Albanian there are fifteen negative suffixes and in English only five, English is much more productive. Considering the lexicographic reflection of words with negative affixes in English-Albanian and Albanian-English dictionaries a brief panorama of both languages lexicographies is provided.

\subsection{The Development of English Lexicography}

The beginnings of English lexicography start with glosses dating somewhere between 600 and 700 AD. This can be distinguished from the four most ancient dictionaries that have come up to day, known, as Leiden, Epinal, Erfurt, and Corpus [Murray A.H 1900]. English Lexicology starts with English-Latin "Promptuarium Parvulorum" compiled by Galfridus, around 1440 and originally published by Richard Pynson in 1499. For the first time the main object was to highlight the English lexical wealth not the Latin one. About the middle of the century was compilled the Medulla Grammtices which formed the basis of Ortus vocabulary. [Murray A.H 1900] Promptuarium as well as Ortus Vocabulorum were published by Uinkin de Uord in one volume for ease of use. Vocabulorum Ortus ("Garden of Words), the first printed Latin-English dictionary issued from the press of Winking de Worde [Winkin de Worde 1500-1516].

In 1483 the Anglicum Catholicon or the universal treaty was compiled and it was thus named due to the name of the famous Latin dictionary, Catholicon, in 1286. Catholicon was an almost as valid work as Promptorium. In 1604, 
Robert Cawdrey, published the Alphabetical Table of Difficult Words. The Work was published for the third time in 1612. In 1616, Dr. John Bullokar published another work of the same type and size, known as an English Expositor, which was published in 1684. In 1623 the lexicographer Henri Cockeram published the first work entitled as Dictionarie, and the third Dictionary of English.

There are published six editions of Sir Thomas Elyot and Cooper, in 1565, in his Thesauri Linguæ Romanæ et Britannicæ. Thesauri later were the basis of Latin-English dictionaries, and their traces can still be detected in these dictionaries.

In the eighteenth century, we largely face the work of Dr Johnson, but in the middle of this century, Natanael Bailey's as well. Bailey was the author of several works, but his great work was "A Universal etymological dictionary of English, published in 1721. In the early nineteenth century, Johnson's vocabulary supremacy was indisputable.

But only two independent contributions to the development of English lexicography are made in the first half of the nineteenth century. The American work of Noah Webster, and the English work of Dr Charles Richardson, "A new English dictionary" with illustrations and citations by Charles Richardson (1836), still continues to be a valuable repertoire. "A new English dictionary" based on historical principles founded mainly on the materials collected by the Philological Society. The latter requires not only every word that has been used in English for the last 800 years, with its written form, its meaning, and pronunciation of the actual words, but it also gives a biography of each word, providing as much information as possible regarding its birth or its first known appearance, and, in the case of an outdated word given its recent appearance, the source from which the word is extracted, and successive changes of form and meaning that it has undergone over the years.

\subsection{The Development of Albanian Lexicography}

The Geography of bilingual lexicography (English-foreign language and vice versa) is very wide, from America to Japan. Albanian bilingual dictionaries cover almost all Indo-European languages, even Bulgarian, Czech, Danish, Norwegian, Polish, Romanian, etc... as well as non-Indoeuropean languages as Arabic, Estonian, Hungarian, etc.. Many bilingual dictionaries came into the Albanian lexicography in the last decade of the 20-th century and in the years of the 21-st century [Thomai, J. 2008].

Nowadays Albanian faces English mostly. English is also part of the curriculum of academic syllabus of Albanian universities. We can mention: English-Albanian dictionary (1986) by llo Stefanllari; Albanian-English dictionary(1988) by Ilo Duro dhe Ramazan Hysa, English-Albanian dictionary(1999), by Ramazan Hysa; Phraseological English-Albanian dictionary (1998), by Ilo Stefanllari; Oxford Albanian-English dictionary (2000), with over 85.000 words, by Leonard Newmark; Albanian-English by Pavli Qesku (1999), with over 45.500 words, English-Albanian dictionary (2002), with over 120.000 words etc..

The history of Albanian lexicography has passed 370 years. It is the earliest and the richest field in our linguistics. We can say that Albanian language history starts with a dictionary without mentioning "the small dictionaries of" Arnold von Harf (1497) and Pjetër Mazreku (1633). The first stone on the long path of Albanian lexicography remains "The LatinAlbanian" (Dictionarium latino-epiroticum, 1635) by Frang Bardhi, with over 2500 Albanian words and 5000 Latin ones).

Since then until the midst of the 20-th century over 100 dictionaries have been compiled. Until 1912 lexicography had served as a way to preserve the Albanian language. Bilingual dictionaries show the Albanian efforts to promote Albanian language. During the 19-th century C. Christophorides compiled a specific Albanian dictionary, (Leksikon tis allvaniqis gllossis,) in Athens, 1904, that served as a bilingual dictionary [Kostallari. A. 1968, Lloshi 1977]. Afterwards the dictionary of "The Union society" was published in 1908 and a dictionary was compiled by Thimi Hondro in 1927. In 1854 the Albane sische Studien by Johan Georg Fon Han, was published and the Albanian-German dictionary which also marks the beginnings of Albanology. It's also worth mentioning Christophorides who helped Hahn in compiling his dictionary. This trend has started with the dictionaries of William Martin Leake (1814) and JR Xylander (1835), to be followed by August Dozone (1879), Holger Pederson (1894) etc.. In 1901 Sami Frashëri compiled Kamus-i túrki; Kamusi fransevi (in 1882), Kamus-i fransevi (in 1885), Kamus-i Arabi and an encyclopaedia Kamusul alam (1900) in six volumes. During 1912-1939, many bilingual dictionaries were published [Lloshi, Xh. 1975]. In the middle of the 20-th century, the final crystallization of Albanian as a unified national standard language was achieved [See Kostallari 1984]. Nowadays Albanian Lexicology and Lexicography constitute specific linguistic disciplines, with a corresponding theory. [Lloshi, Xh. Thomai, J. 1969]. In comparison with the three previous centuries about twice as many dictionaries are compiled in the middle of the 20-th century.

With a literary norm setting, according to Kostallari (1968) and Lloshi (1965), Albanian language vocabulary is 
presented with a complete system. Today Albanian dictionaries are based only on lexical items documented in the dossier of the Albanian language vocabulary. After the Albanian monolingual dictionary publishing in 1954 and especially the Essential Dictionary of Modern Albanian in1980, bilingual dictionaries have a new basis, because Albanian dictionary has been an object of study for many linguistic studies. Since 1950 onwards Albanian lexicography was developed in Kosovo as well. The emigration of Albanians according to [Lloshi 1984] explains the publication of English-Albanian dictionaries in U.S.A early this century, as well as several other dictionaries in Italy. The researcher J. Thomai asserts that Albanian bilingual lexicography in its second period has had a significant increase not only quantitatively, but also qualitatively. He also asserts that "Bilingual lexicography has preceded and helps monolingual lexicography, also solving some key issues of the theory of lexicography" [Thomai, J. 2008].

\section{Productivity of Negatively Affixed Words in the English-Albanian Dictionary of Small Type With 30,000 Words Published by llo Stefanllari in 1986}

While compiling it, many dictionaries of present-day Albanian and English, bilingual and monolingual, especially the dictionary of current Albanian language published in 1980 as well as various terminological dictionaries have been exploited"[ Stefanllari, I. 1986]. Regarding the words with negative meaning, which have historical and qualitative value, plenty of basic material has been collected, even though it is the smallest dictionary English-Albanian that we have analysed.

In tables 1 and 2, all the affixes with negative meaning and the number of words they form are shown.

Table 1. Prefixes with negative meaning and the number of words they form in English-Albanian dictionary of the small type with 30,000 words

\begin{tabular}{|c|c|c|c|c|c|c|c|c|}
\hline \multirow{4}{*}{ Prefixes } & a-/an- & anti- & contra- & counter- & de- & dis- & il- & im- \\
\cline { 2 - 9 } & 11 & 27 & 16 & 27 & 95 & 285 & 12 & 84 \\
\cline { 2 - 9 } & in- & ir- & mal- & mis- & non- & pseudo- & un- & under- \\
\cline { 2 - 9 } & 333 & 53 & 25 & 79 & 26 & 2 & 308 & 12 \\
\hline
\end{tabular}

In this dictionary of small type is distinguished the significant dominance of the most productive prefix in- with 333 words, followed the prefix by un- with 308 words, then the prefix dis- with 285 njësi, im- with 84 words and mis- with 79 words. The rest are not very productive.

Table 2. Suffixes with negative meaning and the number of words they form in English-Albanian dictionary of small type with 30,000 words

\begin{tabular}{|c|c|c|c|}
\hline \multirow{2}{*}{ Suffixes } & -ard & -ish & -less \\
\cline { 2 - 4 } & 10 & 5 & 121 \\
\hline
\end{tabular}

We note the significant dominance of the suffix -less with 121 words. Other suffixes are less productive.

\subsection{Productivity of negatively affixed words in English-Albanian dictionary of small type with 60.000 words published by R. Hysa in 1998.}

During his work with bilingual dictionaries as an editor and a lexicographer, Ramazan Hysa has brought to light a rich lexiocographic material, this way reflecting the Albanian language growth and innovations displayed in English during 1994-1996. In Tables 3 and 4 the affixes with negative meaning and the number of words they form are shown.

Table 3. Prefixes with negative meaning and the number of words they form in English-Albanian dictionary of the medium type with 60000 words.

\begin{tabular}{|c|c|c|c|c|c|c|c|c|c|}
\hline \multirow{4}{*}{ prefixes } & a-/an- & anti- & contra- & counter- & de- & di- & dis- & dys- & il- \\
\cline { 2 - 10 } & 60 & 36 & 20 & 36 & 224 & 4 & 302 & 4 & 21 \\
\cline { 2 - 10 } & im- & in- & ir- & mal- & mis- & non- & pseudo- & un- & under- \\
\cline { 2 - 10 } & 117 & 342 & 41 & 36 & 100 & 59 & 4 & 673 & 12 \\
\hline
\end{tabular}


We note the significant dominance of the prefix un- with 673 words, in- with 342 words followed by dis- with 302 words, then de- with 224 words, and im- with 117 words. The other prefixes are not very much productive.

Table 4. Suffixes with negative meaning and the number of words they form in English-Albanian dictionary of the medium type with 60.000 words

\begin{tabular}{|c|c|c|c|c|c|}
\hline suffixes & -ard & -aster & -ish & -ling & -less \\
\hline & 12 & 1 & 16 & 8 & 230 \\
\hline
\end{tabular}

We note the dominance of the suffix -less as in every dictionary. The other suffixes are not very productive

2.2 Productivity of words with negative affixes in English-Albanian dictionary of big type with 120.000 words pulished by P. Qesku in 2002

A dictionary is a work that holds within it all the lexical information of a language that serves all its society [Xhuvani, A. 1972].

Regarding the formation of words with negative meaning, 5382 words are countered in English-Albanian dictionary of big type by P. Qesku. A dictionary gives clear usage rates of words entering the lexicon of literary language. [Kostallari 1972:14] This dictionary is also normative, explanatory and informative, which means that it meets the requirements that our society sets related to the standard language terms.

Translation is best achieved by finding counterparts with negative affixes in Albanian, sometimes this equivalence is synonimic as for e.g. contretemps \{kentวto\} em Vështirësí (pengésë) e paprítur (pg.356), nonage \{'nounid3\} em • Miturí; móshë e mítur. ( pg.1083).

This dictionary also provides the stylistic characteristics of words.

In Tables 5 and 6 the negative affixes and the number of words they form in this dictionary are shown.

Table 5. Prefixes with negative meaning and the number of words they form in English-Albanian dictionary of the large type with 120.000 words.

\begin{tabular}{|c|c|c|c|c|c|c|c|c|c|}
\hline \multirow{4}{*}{ Prefixes } & a-/an- & anti- & contra- & counter- & de- & dis- & dys- & il- & im- \\
\cline { 2 - 10 } & 99 & 176 & 47 & 120 & 436 & 713 & 17 & 25 & 190 \\
\cline { 2 - 11 } & in- & ir- & mal- & mis- & non- & pseudo- & un- & under- & \multicolumn{1}{|c}{} \\
\cline { 2 - 11 } & 789 & 82 & 74 & 292 & 166 & 29 & 2328 & 133 \\
\hline
\end{tabular}

We note the significant dominance of un- with 2328 words, followed by in- with 789 words, then dis- with 713 words, mis-292, im- with 190 words, anti- with176 words, im- 190 words, non- 166 words, under- 133, and counter- with 120 words. The other prefixes are less productive.

Table 6. Suffixes with negative meaning and the number of words they form in English-Albanian dictionary of the large type with 120.000 words.

\begin{tabular}{|c|c|c|c|c|c|}
\hline Suffixes & -ard & -aster & -ish & -ling & -less \\
\hline & 12 & 4 & 28 & 4 & 515 \\
\hline
\end{tabular}

We note the dominance of the suffix -less with 515 words. The suffix -ish with only 28 words with negative meaning, (it creates other non negative words) -ard with 12 words, followed by -ling and -aster with 4 words respectively in a dictionary of this type, the biggest English-Albanian dictionary existing today.

\section{On the Following the Words with Negative Affixes in Albanian-English Bilingual Dictionaries of Small Medium and Large Type are Lexicographically Presented}

3.1 Productivity of negatively affixed words in Albanian-English dictionary of small type with 20. 000 words compiled by I. Duro and R. Hysa

In this dictionary, the writen and spoken Albanian are clearly reflected. Albanian is characterized by a clear and dominant 
trend to fill with its lexical and word formation means, the requirements set by its society [Kostallari 1972:10].

In Tables 7 and 8 affixes with negative meaning and the number of words they form are shown.

Table 7. Prefixes with negative meaning and the number of words they form in Albanian-English dictionary of small type with 20000 words.

\begin{tabular}{|c|c|c|c|c|c|c|c|c|}
\hline \multirow{4}{*}{ Prefixes } & anti- & ç- & de- & dis- & il- & im- & ir- & in- \\
\cline { 2 - 9 } & 23 & 54 & 23 & 2 & 4 & 1 & 1 & 12 \\
\cline { 2 - 9 } & keq- & kundër- & mos- & nën- & Pa- & sh- & z- & zh- \\
\cline { 2 - 9 } & 12 & 12 & 37 & 8 & 515 & 82 & 7 & 45 \\
\hline
\end{tabular}

Table 8. Suffixes with negative meaning and the number of words they form in Albanian-English dictionary of small type with 20000 words.

\begin{tabular}{|c|c|c|c|c|c|}
\hline \multirow{3}{*}{ Suffixes } & $-a c$ & $-a c a k$ & $-a c ̧$ & -alaq & -alec \\
\cline { 2 - 6 } & 4 & 10 & 4 & 1 & 2 \\
\cline { 2 - 6 } & $-a k$ & $-a n e c$ & $-a r a k$ & $-a v e c$ & $-k e q$ \\
\cline { 2 - 6 } & 6 & 1 & 10 & 3 & 4 \\
\hline
\end{tabular}

We notice that not every suffix with negative meaning is included, only 9 of them as well as the adverb -keq which is the counterpart of the combining form mal-. The adverb -keq is presented with 11 words followed by the negative suffixes acak and -arak with 10 words respectively. The others are not very productive

\subsection{Productivity of negatively affixed words in the Albanian-English dictionary of medium type with 45.500 lexical words published by Pavli Qesku in 2002}

This volume has a considerable number of words with negative meaning affixes, which again shows the value of these words in these dictionaries.

In tables 9 and 10 affixes with negative meaning and the number of words they form are shown.

Table 9. Prefixes with negative meaning and the number of words they form in Albanian-English dictionary of medium type with 45.500 words.

\begin{tabular}{|c|c|c|c|c|c|c|c|c|c|c|}
\hline \multirow{4}{*}{ Prefixes } & a- & anti- & ç- & de- & dis- & dez- & il- & im- & in- & ir- \\
\cline { 2 - 11 } & 10 & 101 & 208 & 79 & 24 & 6 & 4 & 1 & 7 & 3 \\
\cline { 2 - 11 } & jo- & keq & kundër & mos- & nën- & pa- & pseudo- & sh- & z- & zh- \\
\cline { 2 - 11 } & 42 & 29 & 76 & 53 & 13 & 874 & 17 & 494 & 11 & 135 \\
\hline
\end{tabular}

We notice the domination of the most productive prefix in Albanian pa- with 515 words, followed by sh- with 484 words, ç- with 208 words, zh- with 135 words, anti- and de- with 101 and 79 respectively. The other prefixes are not very much productive.

Table 10. Suffixes with negative meaning and the number of words they form in Albanian-English dictionary of medium type with 45.500 words.

\begin{tabular}{|c|c|c|c|c|c|c|c|c|}
\hline \multirow{4}{*}{ Suffixes } & - ac & -acak & -aç & -ak & -alaq & -aluq & -alec & -anec \\
\cline { 2 - 9 } & 15 & 20 & 12 & 16 & 6 & 2 & 1 & 1 \\
\cline { 2 - 9 } & - arak & - araq & - -aq & -avec & $-e c$ & keq & -vec & -uc \\
\cline { 2 - 9 } & 15 & 1 & 7 & 3 & 2 & 44 & 2 & 6 \\
\hline
\end{tabular}

We notice that among negative suffixes and word forming elements the most productive is the adverb -keqe with 44 words followed by suffixe -acak with 20 words -ak with 16 words, and -arak with 15 words. The other suffixes are not very productive. 


\subsection{Productivity of negatively affixed words in Albanian-English dictionary of the large type with more than 85. 000} words and 150.000 translations compiled by Leonard Newmark

It is estimated as the most reliable and the most comprehensive dictionary of modern Albanian. This contemporary dictionary is an achievement in the bilingual English-English lexicography, as it includes standard language besides many dialectical and conversational words.

In Tables 11 and 12 affixes with negative meaning and the number of words they form are shown.

Table 11. Prefixes with negative meaning and the number of words they form in Albanian-English dictionary of the large type with 85.000 words.

\begin{tabular}{|c|c|c|c|c|c|c|c|c|c|}
\hline \multirow{6}{*}{ Prefixes } & a- & anti- & ç- & de- & dis- & dez- & diz- & dys- & il- \\
\hline & 13 & 68 & 296 & 60 & 9 & 5 & 1 & 1 & 5 \\
\hline & im- & in- & ir- & jo- & keq- & kundër- & mos- & nën- & pa- \\
\hline & 4 & 14 & 3 & 52 & 30 & 86 & 110 & 7 & 1280 \\
\hline & pseudo- & sh- & z- & zh- & & & & & \\
\hline & 17 & 438 & 20 & 137 & & & & & \\
\hline
\end{tabular}

We notice the domination of the prefix pa- with 1280 words, followed by sh- with 438 words, ç- with 296 words, zh- with 137 words, mos- 110 words. The other prefixes are less productive.

Table 12. Suffixes with negative meaning and the number of words they form in Albanian-English dictionary of the large type with 85.000 words.

\begin{tabular}{|c|c|c|c|c|c|c|c|c|c|c|}
\hline \multirow{4}{*}{ Suffixes } & - ac & -acak & - aç & -ak & -alak & -alaq & -alec & -aluq & -aq & -arak \\
\cline { 2 - 11 } & 25 & 20 & 18 & 26 & 1 & 12 & 1 & 1 & 2 & 14 \\
\cline { 2 - 11 } & -araq & -arrak & - ash & araq & -avec & - -ec & -keq & -keqe & -uc & -vec \\
\cline { 2 - 11 } & 1 & 1 & 2 & 2 & 3 & 10 & 44 & 1 & 6 & 2 \\
\hline
\end{tabular}

We notice the domination of the suffix -ak with 26 words, followed by-ac with 25 words, -acak with 20 words,-aç and arak with 18 and 14 words respectively. The others are not very much productive.

\section{The Comparison of Dictionaries}

In the following, six dictionaries in number and percentage are shown compared with one another within the same referring language.

Table 13. The average in number, percentage, for affxed words with negative meaning in the three English-Albanian dictionaries

\begin{tabular}{|c|c|c|c|c|}
\hline English-Albanian dictionaries & \multicolumn{2}{|c|}{ prefixes } & \multicolumn{2}{c|}{ suffixes } \\
\hline & number & $\%$ & number & $\%$ \\
\hline 30,000 words & 1395 & 4.65 & 136 & 0.45 \\
\hline 60,000 words & 2089 & 3.48 & 267 & 0.44 \\
\hline 120,000 words & 5716 & 4.76 & 563 & 0.47 \\
\hline \multirow{2}{*}{} & average & 4.30 & average & 0.46 \\
\hline
\end{tabular}




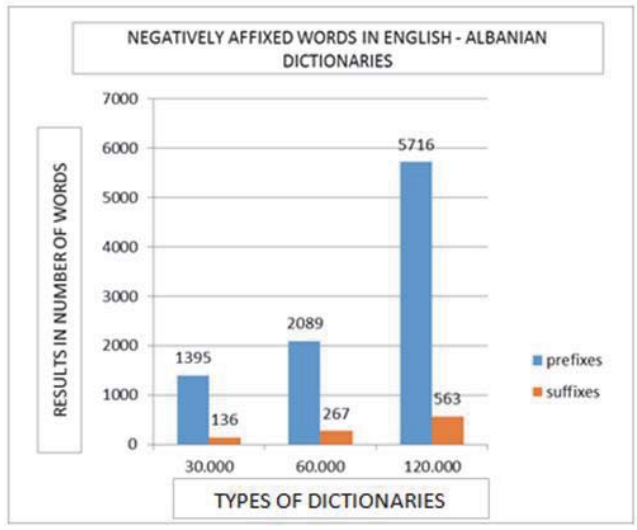

Figure 1. The number of words with negative affixes in the three English -Albanian dictionaries

\subsection{The statistical analysis of English-Albanian dictionaries in number}

After comparing the 30.000 words dictionary with the 60.000 word one, it is obvious that the ratio in number of words for the respective ones is twice larger. In words with negative prefixes it is 1.5 times larger and in suffixed words it is 1.9 times larger. From a viewpoint of words with negative prefixes, it results that the small-type dictionary is much more productive than the medium-type dictionary.

After comparing the dictionary with 60.000-words with the 120.000 words one, it is clear that the ratio in number of words for the respective ones is twice larger. In words with negative prefixes it is 2.7 times larger, and in suffixed words it is 2.1 times larger. From the point of view of prefixation it results that the medium-type dictionary with 60.000 -words is not very productive compared to the one with 120.000-words of the large type, whereas from the point of view of suffixes, their number is nearly proportional with the number of words in the dictionary.From the generalized statistics the prefixed words with negative meaning dominate.

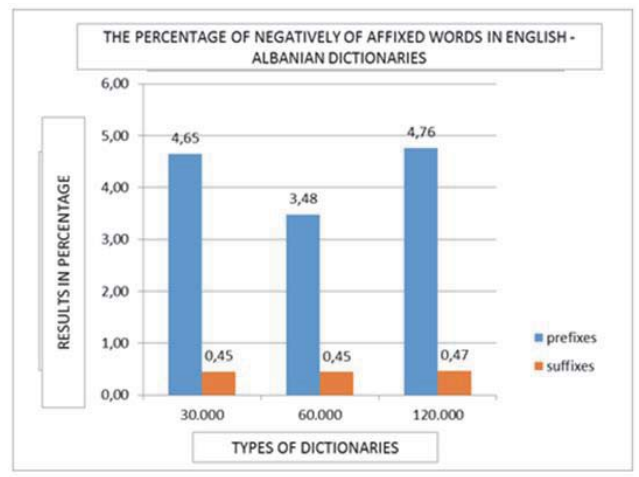

Figure 2. Results in percentage for negatively affixed words in English-Albanian dictionaries.

In the English-Albanian dictionary of small type, with 30.000 words by I. Stefanllari, words with negative prefixes occupy $4.65 \%$, and words with negative suffixes occupy $0.45 \%$.

In the English-Albanian dictionary of medium type with 60.000 words by R. Hysa, words with negative prefixes occupy $3.48 \%$ and words with negative suffixes occupy $0.45 \%$.

In English-Albanian dictionary of large type by P. Qesku words with negative prefixes occupy $4.76 \%$ and words with negative suffixes occupy $0.47 \%$. 


\subsection{The statistical analysis of English-Albanian dictionaries in percentage}

After comparing English-Albanian dictionary with 30.000 words, with English-Albanian dictionary with 60.000 words, results that the ratio in percentage of words for the respective dictionaries is $1.17 \%$ more in words with negative prefixes in comparison with the dictionary of medium type. In relation to words with negative suffixes in English-Albanian dictionary of medium type with 60.000 words, results that values in percentage are equal, indicating that the dictionary of the small type is much more productive in words with negative affixes.

After comparing the English-Albanian dictionary with 30.000 words of the small type with the English-Albanian dictionary of the large type with 120.000 words by P. Qesku, it is expected that the dictionary of the large type being 4 times larger in number of words, to have many more negatively affixed words, but the difference is $0.11 \%$ more, in words with negative prefixes whereas in words with negative suffixes the difference is $0.02 \%$ more. It results that the dictionary of small type with 30.000 meets the requirements with words with negative affixes being in service of antonymy and polysemy as well.

After comparing the English-Albanian dictionary of medium type with 60.000 words with me the English-Albanian dictionary of large type with 120.000 words, the latter includes $1.27 \%$ less words with negative prefixes. The result is expected, so $2 \%$ less because the dictionary with 60.000 words is 2 times smaller than the dictionary of the large type. In relation with the negatively suffixed words, the dictionary of medium type with 60.000 words has almost $0.02 \%$ words less than the dictionary of the large type.

In words with negative prefixes, the English-Albanian dictionary of small type with 30.000 words is the most productive of the three. In words with negative suffixes the English-Albanian dictionary of medium type is the most productive of the three.

We notice that in English-Albanian dictionaries about $4 \%$ of the words are negatively prefixed.

The frequency of negatively prefixed words is larger than the frequency of negatively suffixed words in both languages.

Table 14. Number, percentage, and the average of percentages in negatively affixed words in Albanian-English dictionaries

\begin{tabular}{|c|c|c|c|c|}
\hline \multirow[t]{2}{*}{ Albanian-English } & \multicolumn{2}{|c|}{ Prefixes } & \multicolumn{2}{|c|}{ Suffixes } \\
\hline & number & $\%$ & number & $\%$ \\
\hline 20.000 & 838 & 4.19 & 45 & 0.23 \\
\hline 45.500 & 2187 & 4.81 & 153 & 0.34 \\
\hline 85.000 & 2656 & 3.12 & 172 & 0.20 \\
\hline & avearage & 4.04 & & 0.25 \\
\hline
\end{tabular}

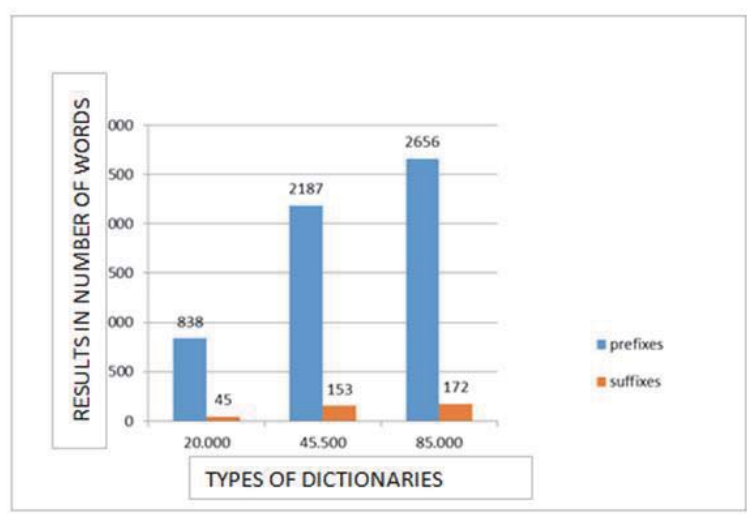

Figure 3. The number of negatively affixed words in Albanian-English dictionaries 


\subsection{The statistical analysis of Albanian-English dictionaries in number}

After comparing the Albanian-English dictionary with 20.000 words of the small type with the Albanian-English dictionary with 45.500 words of the medium type, it results that the ratio in number of words in total is 2.2 times larger. From a viewpoint of words with negative prefixes, it results to be 2.6 times larger. From a viewpoint of words with negative suffixes, it results that the dictionary of medium type with 45.500-words is 3.4 times larger. It is noticed that the AlbanianEnglish dictionary with 45.500-words is relatively denser than the 20,000-words dictionary.

After comparing the Albanian-English dictionary with 45.500-words of medium type with the Albanian-English dictionary of the large type with 85.000-words, it results that in relation with the total number of words in total it is 1.8 times larger than the dictionary of the medium type.While comparing the negatively prefixed words, it results that the dictionary of the large type is 1.2 times larger, whereas while comparing the negatively suffixed words it is 1.1 times larger. It is noticed that the dictionary of medium type is more productive in words with negative affixes than the dictionary of the large type.

After comparing the Albanian-English dictionary of the small type with 20.000-words with the Albanian-English dictionary of large type with 85.000 -words, it results that in relation to the number of words in total it is 4.2 times larger than the dictionary of the large type, whereas while comparing them with regard to words with negative prefixes, it results that the dictionary of the large type is 3.1 times larger, and while comparing it with regard to words with negative suffixes, it results 3.8 times larger. It is noted that the dictionary of the small type is much more productive in words with negative affixes than the dictionary of the large type.

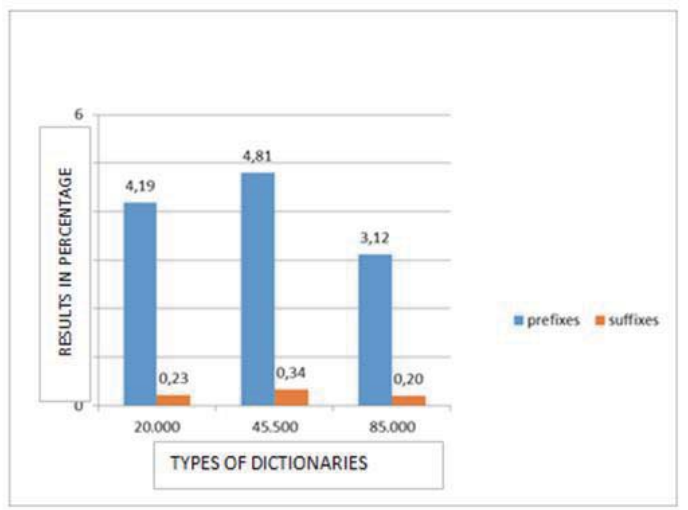

Figure 4. Results in percentage in words with negative affixes in Albanian - English dictionaries

\subsection{The statistical analysis of Albanian- English dictionaries in percentage}

In the Albanian-English dictionary of the small type, with 20.000 words by I. Duro and R. Hysa, the words with negative prefixes represent $4.19 \%$ and the words with negative suffixes $0.23 \%$, respectively.

In the Albanian-English dictionary of the medium type with 45.500 words by P. Qesku, the negatively prefixed words occupy $4.81 \%$ and the negatively suffixed words take $0.34 \%$.

In the Albanian-English dictionary of the large type with 85.000 words by P. Newmark, words with negative prefixes occupy $3.12 \%$ and words with negative suffixes occupy $0.20 \%$.

It is noted that in Albanian-English dictionaries over $4 \%$ of the words in total are occupied by words with negative prefixes. The frequency of words with negative prefixes is larger than the frequency of words with negative suffixes.

After comparing the Albanian-English dictionary with 20.000 words of the small type with the Albanian-English dictionary with 45.500 words of medium type, it results with $0.62 \%$ more words with negative prefixes in the 45.500 words dictionary. Regarding words with negative suffixes, the Albanian-English dictionary with 45.500 words has $0.11 \%$ many more negative words. It is an expected result due to the larger number of words in total ( 25.000 more words).

After comparing the Albanian-English dictionary of 20.000 words with the Albanian-English dictionary with 85.000 words, it is expected that the latter being nearly 4.2 times larger in number of words to have many more words, but the 
difference in words with negative prefixes is $1.07 \%$ less in the 85.000 words dictionary, whereas in words with negative suffixes, the difference is $0.03 \%$ less than in the dictionary of the large type.

After comparing the Albanian-English dictionary of 45.500 words with the Albanian-English dictionary of 85.000 words, the latter results with $1.69 \%$ less words with negative prefixes than the dictionary of medium type. The dictionary of medium type has $0.14 \%$ many more words with negative prefixes than the dictionary of the large type. In words with negative affixes, the dictionary of the medium type is the most productive of the three.

The dictionary of the small type meets the requirements with lexemes with negative affixes serving to antonymy and polysemy as well. The growth of words in number in a dictionary does not not necessarily show an increase in the number of words with negative affixes. The number of these words is not in proportional with the number of all the words in the dictionary.

\subsection{The average frequency of words with negative affixes in both languages}

In the following, the average frequency of words with negative affixes in Albanian-English and English-Albanian dictionaries is shown.

Table 15. The average frequency words with negative affixes in Albanian-English and English-Albanian dictionaries

\begin{tabular}{|l|c|c|c|c|}
\hline The dictionary & \multicolumn{2}{|c|}{ English-Albanian } & \multicolumn{2}{c|}{ Albanian-English } \\
\hline Affixes & prefixes & suffixes & prefixes & suffixes \\
\hline Average & 4.3 & 0.46 & 4.04 & 0.25 \\
\hline
\end{tabular}

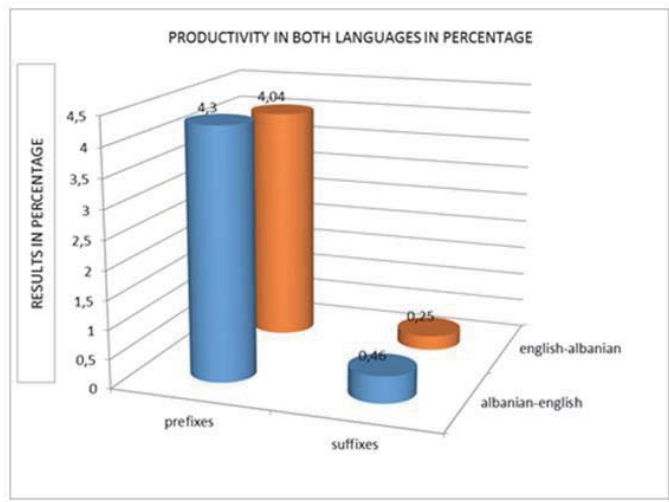

Figure 5. The average frequency in percentage of words with negative affixes in Albanian-English and English-Albanian dictionaries

\section{Conclusions}

As a result of the lexicographic reflection of words with negative affixes in each English-Albanian and Albanian-English dictionaries of small, medium and large type, the place that these words occupy in each language is determined. Judging by the average of the obtained results for each dictionary category, is concluded that the words with negative prefixes in English occupy $4.3 \%$, words with negative suffixes occupy $0.46 \%$, whereas in Albanian the words with negative prefixes occupy $4.04 \%$ and the words with negative suffixes occupy $0.26 \%$.

It is noticed that the number of words with negative prefixes in English is almost equal (with a difference of $0.26 \%$ ) with the number of words with negative prefixes in Albanian. Considering the fact that in English there are 12 negative prefixes and one combining form with negative meaning, whereas in Albanian there are 16 negative prefixes and 2 adverbs with negative meaning, their spreading in Albanian-English and English-Albanian dictionaries is almost equal in both languages. This is due to the fact that a few prefixes in English are much more productive than the Albanian negative prefixes. 
Based on the final statistical comparison, it is noticed that the number of words with negative suffixes is larger in English (with a diference of $0.2 \%$ ) even though English has got only one proper antonymic suffix and four word forming suffixal elements with negative connotation. This productivity is due to the fact that the suffix -less in English forms many more words than the fifteen suffixes and one adverb with negative meaning of Albanian. The results show that EnglishAlbanian dictionaries have many more words with negative suffixes than in Albanian-English dictionaries.

With regard to the word formation with negative affixes, we have concluded that the productivity of these words in both English and Albanian languages, based on the dictionaries of the small, medium and large type, is almost the same, the difference is approximately $0.2 \%$ or two words per 1000 ones. English results with many more negatively affixed words than Albanian. This is due to the fact that English has a richer vocabulary than Albanian and is always open to borrowings, because of its worldwide use. Moreover, English-Albanian dictionaries analyzed are larger in the number of words than Albaninan-English ones.

Finally, the use of these words is important in both languages because they are productive in the adjective fields, in antonymic formation, in polysemy and particles, transforming the latter ones in prefixoids, affixes, word forming elements, indispensable in the linguistic system.

\section{References}

Duro, I. Hysa, R. (1988) Albanian - English dictionary. Tiranë. 8 Nentori Publishing House. pg. 3.

Kostallari, A. 1968. 'Parimet Themelore Për hartimin e Fjalorit Të Gjuhës Së Sotme Shqipe, in Studime Filologjike 1968. No 2: 43-128. Kostallari. A. 1968. Lloshi (1977). Kostallari, A. (1968) 'Parimet Themelore Për Hartimin e 'Fjalorit Të Gjuhës Së Sotme Shqipe' në Studime Filologjike 1968. No 2: 43-128 \& Lloshi, Xh. 1977. 'Fjalori I Kostallarit, A. (1984) 'Gjuha Letrare Kombëtare Shqipe dhe Epoka Jonë ' in "Studime Filologjike" 1984. No 4: 25-55.

Kostallari, A. (1972) Parimet Themelore për hartimin e Fjalorit të gjuhës sotme Shqipe in Studime mbi leksikun dhe mbi formimin e fjalëve në gjuhën Shqipe II Tiranë pg.10 .

Kostallari, A.(1972) Studime Mbi Leksikun Dhe Formimin E Fjalëve II Tiranë, pg 14.

Lloshi, Xh. (1975) 'Muzeu i gjallë i gjuhës — fjalori' in "Shkenca Dhe Jeta" 1975. № 3: 24-26.

Lloshi , Xh. and Thomai, J. (1969) Leksikologjia e Leksikografia Shqipe Paraçlirimit. Studia Albanica 1969. № 2: 105-127.

Lloshi, Xh. (1965) 'Kumtesë Mbi Parimet e Hartimit të Fjalorit të Shqipes Bashkëkohore, Studia Albanica 1965. № 1: 177-178.

Lloshi, Xh. (1984) 'Shqipja Moderne në kontekste të ndryshme kulturore. Studia Albanica 1984. No 2: 165-176.

Murray J. A.h. (1900) The evolution of English lexicography, Oxford, pg.3-8 The project gutenberg ebook. http://www.gutenberg.org/ files/11694/11694-8.txt

Newmark, L. (1999) Albanian-Englsih dictionary. Oxford University Press. Qesku, P. Albanian - English dictionary. EDFA Publishings Tiranë (2002).

Qesku, P. English - Albanian dictionary. EDFA Publishings. Tiranë (2002).

Stefanllari, I. Fjalor Anglisht - Shqip, 8 Nentori Publishing House.Tiranë (1986).

Thomai, J. (2008) Lexicology of Albanian language pg. 358 and 355.

Xhuvani, A (1972) Studime Mbi Leksikun Dhe Formimin E Fjalëve II Tiranë, pg 115.

Wynkyn de Worde The Beginning of English Lexicography London 5 september 1500-1516 http://www.schulz-falster.com/ books/book42.pdf 5 .

Murray J. A.h. (1900) The evolution of english lexicography Oxford Clarendon pressby horacehart, m.a.https://en.wikisource.org/ wiki/the_evolution_of_english_lexicography pg 16 